\title{
Effect of Duty Ratio at Different Pulse Frequency during Hole Drilling in Ceramics Using Electrochemical Discharge Machining
}

\author{
Pankaj Kumar Gupta ${ }^{1}$, Jai Prakash Bhamu ${ }^{1}$, Chandra Shekhar Rajoria ${ }^{1}$, Nitin Kumar Lautre ${ }^{2}$, Vishnu Agarwal ${ }^{3}$ \\ ${ }^{1}$ Department of Mechanical Engineering, Engineering College, Bikaner (Raj.) - India. \\ ${ }^{2}$ Department of Mechanical Engineering, Visvesvaraya National Institute of Technology, Nagpur (MS.) - India \\ ${ }^{3}$ Department of Mechanical Engineering, GITS, Udaipur (Raj.) - India
}

\begin{abstract}
The Electro Chemical Discharge Machining (ECDM) is a hybridization process of electro chemical and electric discharge machining, which is used for machining of hard, brittle and nonconductive materials. The present paper investigates the effect of duty ratio at different pulse frequency on the four process responses, i.e. material removal rate, depth of penetration, surface damage and heat affected zone of the hole drilled by ECDM. The requirements of a quality drilled hole are to have less surface damage and heat affected zone along with larger depth of penetration and material removal rate. The selected alumina ceramic (A12O3) work piece material is widely used in hi-tech electrical apparatus. The results were characterized by optical microscope and analysed by using pulse wave forms of voltage with time. The results show that the effectiveness of pulse frequency varies according to the desired response characteristics. The research findings provide the most effective duty ratio for an improved quality of drilled hole in ceramics.
\end{abstract}

\section{Introduction}

Electro Chemical Discharge Machining (ECDM) was invented as 'electrical discharge drilling' in 1968 for producing micro holes in nonconductive materials such as glass, ceramic, etc. [1]. ECDM is a combination of the two non-conventional machining methods, namely; electro chemical machining (ECM) and electrical discharge machining (EDM) [2]. The common nonconventional methods used to fabricate the holes in nonconductive work pieces are abrasive jet machining and ultrasonic machining $[3,4]$. However, the application of these processes are restricted due to poor material removal rate, high tool wear, poor surface finish and geometrical inaccuracy [4]. Therefore, ECDM is an alternative approach to machine the nonconductive work materials. The alumina ceramic is most widely used in high temperature electrical insulators and in other electrical applications due to higher strength, stiffness, high wear and corrosion resistance, high thermal stability and excellent insulation as compared to its counter materials. The subsequent section details some of the investigations conducted on variety of ceramics by various researchers.

It was investigated that material removal in ceramics occurred by etching of grains through high temperature electrolyte and melting [5]. Gas Filled Electro discharge Electro Chemical Machining (GFEECM) was developed to machine the ceramics [6]. The ECDM was used for drilling holes on non-conducting zirconium oxide ceramic components [7]. It was reported that effect of tool tip with flat front and taper side wall provides the controlled and effective machining [8].

The literature revealed the need for accurate and precise machining of ceramics. In ECDM, the material is melted by thermal energy and removed by subsequent chemical etching $[9,10]$. This thermal energy is transferred in the workpiece and creates the heat affected zone (HAZ). The HAZ results in cracks on the workpiece surface and distort the hole dimensions. The surface damage (SD) is unwanted material removal and losses the accuracy of drilled hole. Hence, reduction of the HAZ and SD with high material removal rate (MRR) and depth of penetration (DOP) are desirable to produce more accurate holes in ceramics. The HAZ was reduced in a pulse voltage supply, because the hole drilling takes place during the pulse-on-time of the cycle and the material cools during the pulse-off-time [11]. The present article investigates the results of increasing duty ratio at different pulse frequency on the MRR, DOP, SD and HAZ at desirable points of interest. From the results, a favourable machining condition with minimum SD and HAZ along with maximum MRR and DOP was reported.

\section{Experimental Procedure}

An experimental setup was developed in the laboratory [12]. The applied voltage was $65 \mathrm{~V}$ using DC pulse power supply. Rectangular pulse waves with a specific pulse width were supplied. The number of pulse cycles per unit time is pulse frequency. The ratio of 'pulse on 
time' to total pulse cycle time (sum of pulse on time and pulse off time) is termed as duty ratio [11]. The voltage wave forms of pulses were recorded by Digital Storage Oscilloscope (DSO). The pulse frequencies are classified in four sets (in multiple of frequency from $1000 \mathrm{~Hz}$ to 1 $\mathrm{Hz}$ ) according to pulse width as given in Table 1.

Table 1. Sets of Duty ratio According to Pulse Width and Pulse Frequency

\begin{tabular}{|c|c|c|c|c|}
\hline \multirow{2}{*}{ Set } & \multicolumn{2}{|c|}{ Pulse width } & \multirow{2}{*}{$\begin{array}{c}\text { Pulse } \\
\text { Frequency } \\
{[\mathrm{Hz}]}\end{array}$} & \multirow{2}{*}{$\begin{array}{c}\text { Duty } \\
\text { ratio } \\
{[\%]}\end{array}$} \\
\hline & $\begin{array}{l}\text { Pulse on } \\
\text { time }[\mathrm{ms}]\end{array}$ & $\begin{array}{l}\text { Pulse off } \\
\text { time [ms] }\end{array}$ & & \\
\hline $\begin{array}{c}\mathrm{I}(\mathrm{X} 1000 \\
\mathrm{Hz})\end{array}$ & 0.1 & $\begin{array}{l}0.1-0.04- \\
0.01\end{array}$ & $\begin{array}{l}5000-7000- \\
9000\end{array}$ & $\begin{array}{l}50-70- \\
90\end{array}$ \\
\hline $\begin{array}{c}\text { II (X100 } \\
\text { Hz) }\end{array}$ & 1 & $\begin{array}{l}1-0.42- \\
0.11\end{array}$ & $500-700-900$ & $\begin{array}{l}50-70- \\
90\end{array}$ \\
\hline $\begin{array}{c}\text { III (X10 } \\
\text { Hz) }\end{array}$ & 10 & $\begin{array}{l}10-4.28- \\
1.11\end{array}$ & $50-70-90$ & $\begin{array}{l}50-70- \\
90\end{array}$ \\
\hline $\begin{array}{c}\text { IV (X } \\
1 \mathrm{~Hz})\end{array}$ & 100 & $\begin{array}{l}100- \\
42.85- \\
11.11\end{array}$ & $5-7-9$ & $\begin{array}{l}50-70- \\
90\end{array}$ \\
\hline
\end{tabular}

The $\mathrm{NaOH}$ electrolyte with $20 \% \mathrm{wt} / \mathrm{v}$ concentration was used in the experiment at room temperature. A cylindrical stainless steel tool with diameter of $700 \mu \mathrm{m}$ was used. The auxiliary electrode made of graphite was kept at a distance of $40 \mathrm{~mm}$ from tool. The workpiece was a $9 \mathrm{~mm}$ thick alumina ceramic $\left(\mathrm{Al}_{2} \mathrm{O}_{3}\right)$ material.

The schematic of a drilled blind hole produced by ECDM is shown in Fig. 1. After drilling of the ceramic workpiece, the diameters of the top side of hole were measured as HAZ and SD using an optical microscope at $20 \mathrm{X}$ magnification. The HAZ was calculated as the difference in diameters of HAZ and SD, while the SD was the obtained by subtracting the tool diameter from diameter of SD. The DOP was measured by a dial gauge (Mitutoyo). Three specimen were drilled at constant parametric setting. Each experiment was performed for 5 minutes and average results of responses are presented herein.

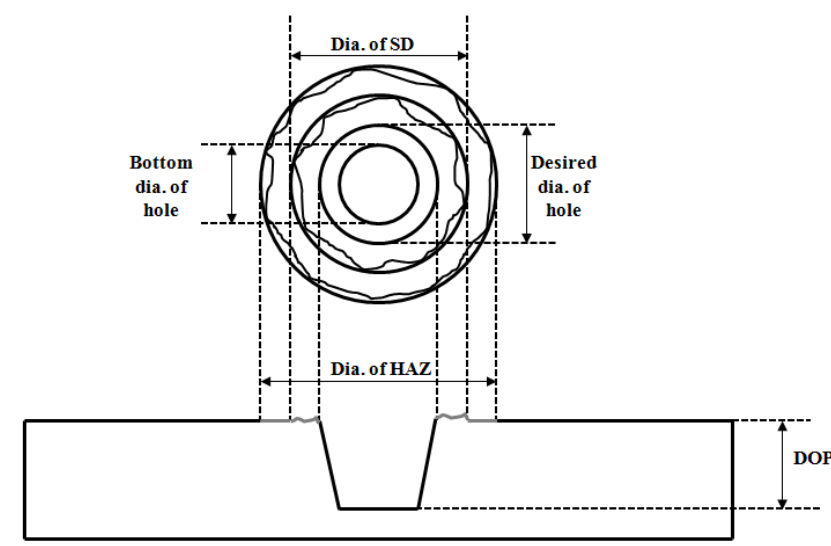

Figure 1. Schematic of the Drilled Hole

\section{Result and Discussion}

Effect of duty ratio was experimentally investigated on ceramic work material at four sets of pulse frequency. The experimental results revealed that the magnitude of all response characteristics i. e. MRR, DOP, SD and HAZ increased with the increase in duty ratio as shown in Figure 2 (a), (b), (c), and (d).
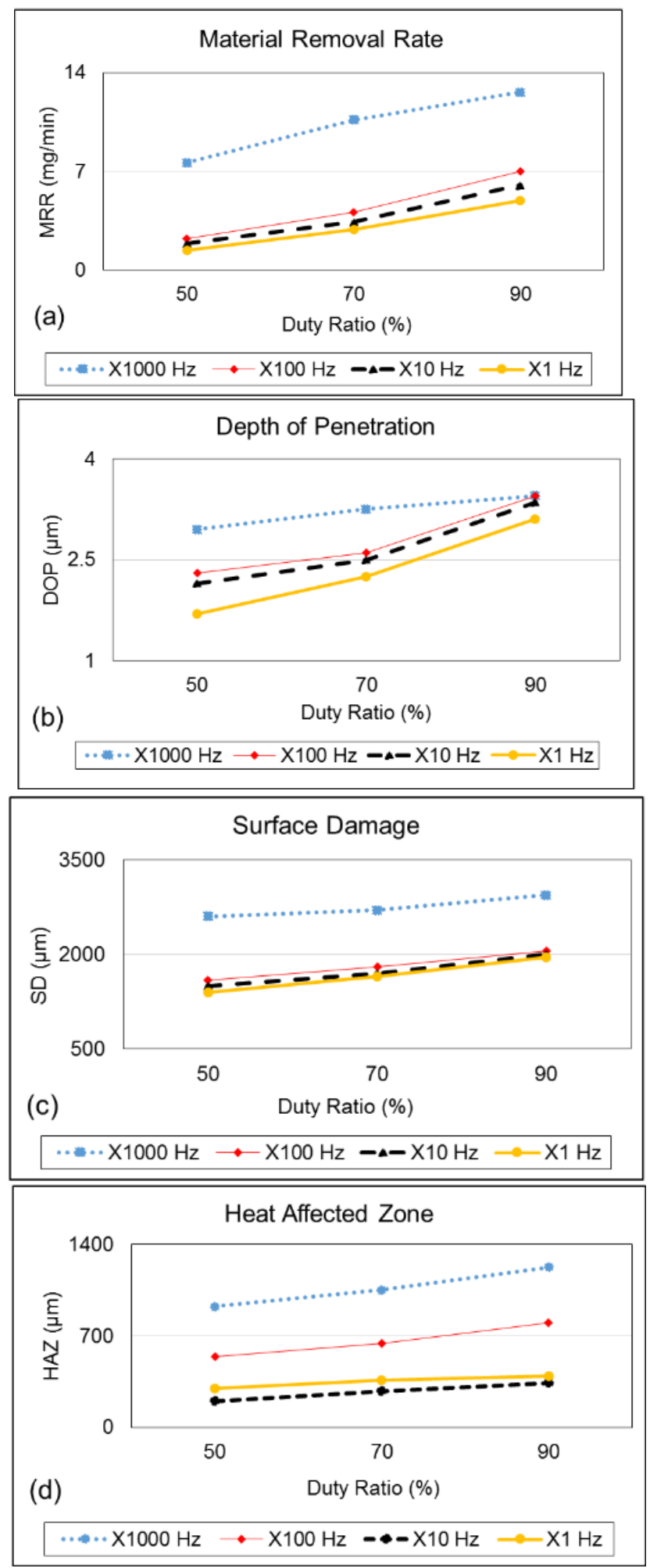

Figure 2. Effect of Duty Ratio at Different Pulse Frequency on Responses 
The reason attributed is that the increase in duty ratio, increases the proportion of voltage applied time (pulse on time). Therefore, duration of thermal energy supply increased with increase in duty ratio. The maximum MRR, DOP, SD and HAZ were observed at 90\% duty ratio in set I as shown in Fig. 2 (a to d)). It is evidenced to the high switching frequency as observed from pulse wave form in Fig. 3 (a) and side discharge [12, 13]. The minimum SD was at $50 \%$ duty ratio, which is almost equal in set II, III and IV (Figure 2-c). It occurs because the effect of pulse off time and pulse on time is equal at this point. It means both pulse width plays equal role as shown in Fig. 3 (b). But HAZ was higher in set-IV as compared to set III at $50 \%$ duty ratio. It seems that longer pulse off time allows to flow the heat in the workpiece during pulse on time sufficiently in set-IV, while in setIII, the pulse off starts to play its role before the pulse on tries to propagate in the workpiece. The hole drilled with minimum HAZ with microscopic image and pulse wave form are shown in Fig. 3 (b).
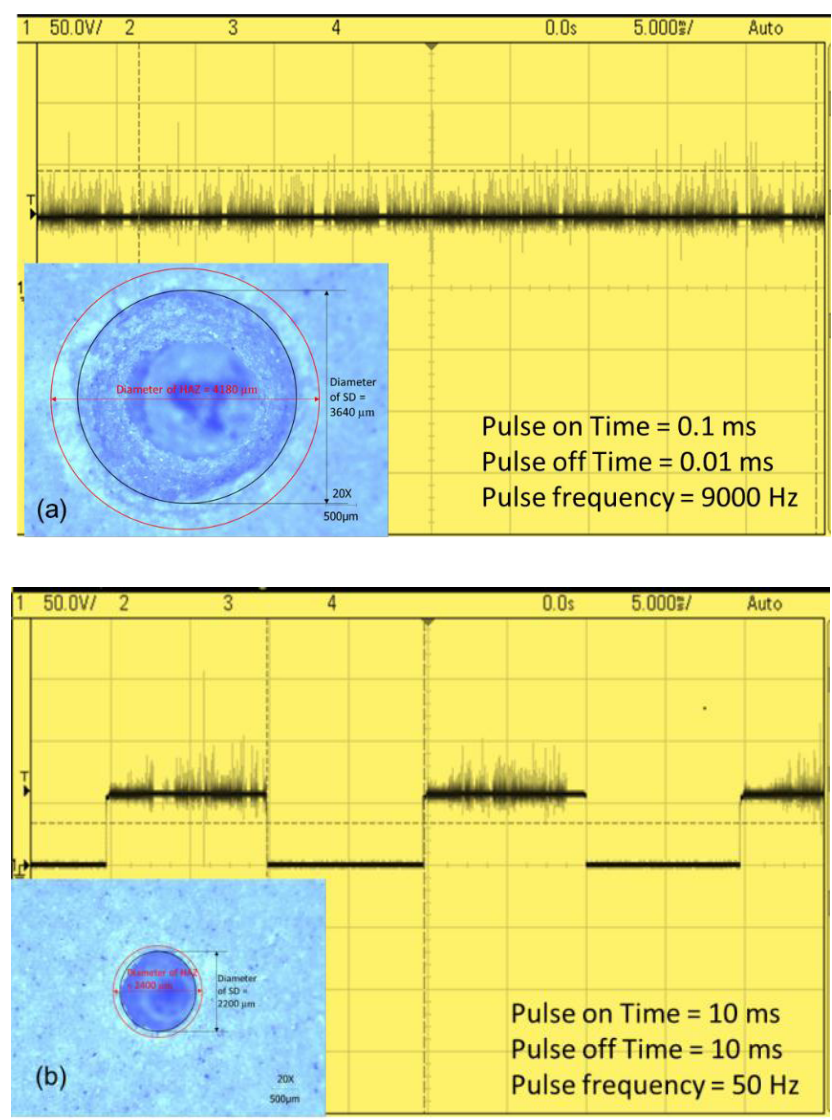

Figure 3. Pulse Wave Forms and Drilled Hole (a) at Maximum MRR Condition (b) at Minimum HAZ Condition

\section{Conclusion}

The holes were drilled at various pulse frequencies. The pulse width decides the frequency in a pulse power supply. All the response characteristics were found increased with increase in duty ratio. However, in order to get accurate and more precise holes with minimum SD and HAZ, compromise is required with MRR and DOP. Therefore, it is concluded that frequencies in multiples of
$\mathrm{X} 10 \mathrm{~Hz}$ are recommended for minimum $\mathrm{HAZ}$ and $\mathrm{SD}$, while the frequency in multiples of $\mathrm{X} 1000 \mathrm{~Hz}$ is preferable for maximum MRR and DOP for drilling of holes in alumina ceramic work material. Results of frequencies in multiples of X100 Hz, X10 Hz and X1Hz are very close for the MRR, DOP and SD.

\section{References}

1. R. Wuthrich, and V. Fascio: Machining of nonconducting materials using electrochemical discharge phenomenon - an overview, Int. J. Mach. Tool. Manuf. Vol. 45 (2005), p. 1095-1108.

2. V. K. Jain and S. Adhikary: On the mechanism of material removal in electrochemical spark machining of quartz under different polarity conditions, J. Mater. Process. Technol. Vol. 200 (2008), p. 460-470.

3. M. C. Panda and V. Yadava: Intelligent modelling and multi-objective optimization of die sinking electro-chemical spark machining process, Materials and Manufacturing Processes. Vol. 27 (2012), p. 1025.

4. Z-P. Zheng, H-C. Su, F-Y. Huang and B-H. Yan: The tool geometrical shape and pulse-off time of pulse voltage effects in a Pyrex glass electrochemical discharge micro drilling process, J. Micromech. Microeng. Vol. 17 (2007), p. 265-272.

5. H. Tokura, I. Kondoh, M. Yoshikswa: Ceramic material processing by electrical discharge in electrolyte. Journal of Materials Science, Vol. 24 (1989), p. 991-998.

6. L. Yonghong, J. Zhixin, L. Jinch: Study on hole machining of non-conducting ceramics by gas-filled electro discharge and electrochemical compound machining, J. Mater. Process. Technol. Vol. 69 (1997), p. 198-202.

7. B. Doloi, B. Bhattacharyya and S. K. Sorkhel: Electrochemical discharge machining of nonconducting ceramics, Defence Science Journal. Vol. 49 (4) (1999), p. 331-338.

8. B. Bhattacharyya, B.N. Doloi and S. K. Sorkhel: Experimental investigations into electro chemical discharge machining (ECDM) of non-conductive ceramic materials. J. Mater. Process. Technol. Vol. 95 (1999), p. 145-154.

9. N. Gautam and V. K. Jain, Experimental investigations into ECSD process using various tool kinematics, Int. J. Mach. Tools Manuf. Vol. 38 (1998), p. 15-27.

10. A. Kulkarni, R. Sharan and G. K. Lal: An experimental study of discharge mechanism in electrochemical discharge machining, Int. J. Mach. Tools Manuf. Vol. 42 (2002), p. 1121-1127.

11. D. J. Kim, Y. Ahn, S. H. Lee, Y. K. Kim: Voltage pulse frequency and duty ratio effects in an electrochemical discharge micro drilling process of Pyrex glass, Int. J. Mach. Tools Manuf. Vol. 46 (2006), p. 1064-1067.

12. P. K. Gupta, A. Dvivedi and P. Kumar: Effect of pulse duration on quality characteristics of blind hole drilled in glass by ECDM, Materials and 
Manufacturing Processes. (2015), doi: 10.1080/10426914.2015.1103857.

13. P. K. Gupta, A. Dvivedi and P. Kumar: Impact of pulse width on hole overcut in an electrochemical discharge machining of blind holes, International Conference on Processing and Fabrication of Advanced Materials XXIII,. IIT Roorkee, Vol. 1 (2014) p. 493-498 